\section{MBE for army hygienist}

An MBE was awarded to Warrant Officer Class 2 Elizabeth Deuchars, a Dental Hygienist of the Royal Army Dental Corps, in this year's Queens Birthday honours list. The award was for her outstanding contribution to the education of Dental Care Professionals and her work with the charity Crisis at Christmas.

\section{Death notice}

Alison Grace Hobbes (née Woodhouse) died on 5 July 2006 after a short illness. Born on 15 October 1943, she qualified BDS in Birmingham in 1958. Alison had a short career in dentistry due to family commitments and back problems, but she still inspired her daughter Felicity Harrison to become an NHS dentist. Widowed 10 years ago, Alison will be sadly missed by daughters Felicity and Caroline, and by her sons Colin and Martin.

\section{New Chief Dental Officer appointed}

Dr Barry Cockcroft is the new Chief Dental Officer for England, it was announced last month. Dr Cockcroft was Acting Chief Dental Officer for England from October 2005 when Chief Dental Officer Professor Raman Bedi left after a three-year secondment. He held the post of Deputy Chief Dental Officer (DCD0) since joining the Department of Health in November 2002 and prior to this he worked for 27 years in NHS general practice. Dr Cockcroft qualified from Birmingham Dental School in 1973. Before he was appointed as DCDO he served on the Warwickshire Local Dental

\title{
Travel awards presented
}

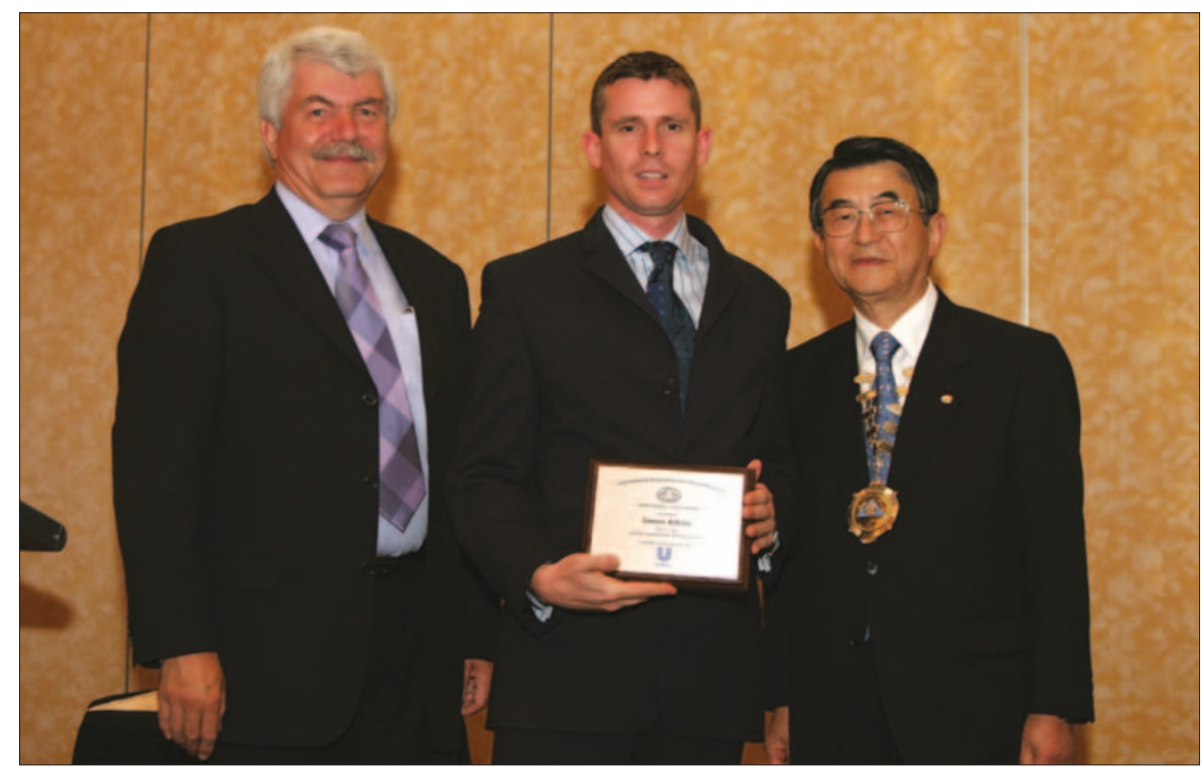

Four UK dental scientists have been presented with IADR/Unilever Division Travel Awards at the International Association for Dental Research 84th General Session and Exhibition opening ceremonies this year. Around 43 individuals from 18 divisions received awards and from the UK they were Dr Maria Nystrom, Dr Jonathan Collier, Dr Simon Atkins, and Dr T. Curran. The awards were established to encourage outstanding young dental scientists to carry out research, attend the annual IADR General Session, and compete in the IADR/Unilever Hatton Awards Competition. Pictured above left to right, Fred Schafer, Unilever, Dr Atkins and Takayuki Kuroda, 2005-2006 President of the IADR Board.

Committee as Chairman and Secretary. He was Chairman of the West Midlands Association of LDCs, and was elected to the General Dental Services Committee (GDSC) of the British Dental Association in 1990. He also served on many subcommittees and working groups of the GDSC before being elected Vice-Chairman in 2000.

Away from dental politics, Dr Cockcroft was the clinical lead in developing and running a first wave personal dental service in Rugby which was based on capitation as a method of remuneration in NHS general practice. He has also served as a magistrate on the Warwickshire bench between 1992 and 2000 and is married with three children.

In accepting the position he said, "I am delighted that as Chief Dental Officer for England I can now push forward our plans to improve the oral health of the country. The key priority for me now is to provide support to Strategic Health Autorities as they consider introducing new fluoridation schemes and start consulting with their local populations."

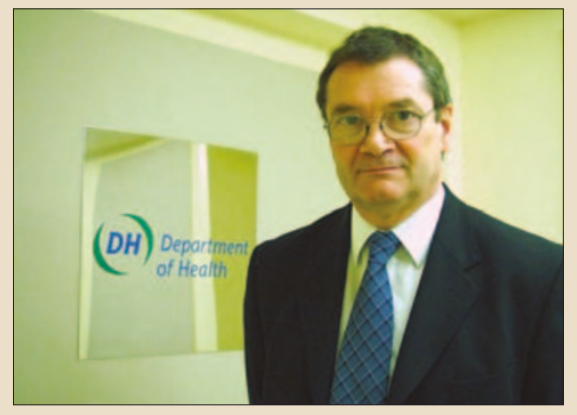




\section{Human skull found}

Dentists are being urged to check their records to help HM Coroners Office, Torbay and South Devon District identify a human skull found by fisherman six miles east of South Point in South Devon.

The individual was possibly a male aged around 40 years old and the skull is intact except for the absence of the mandible. An examination of the maxillary teeth demonstrates all permanent

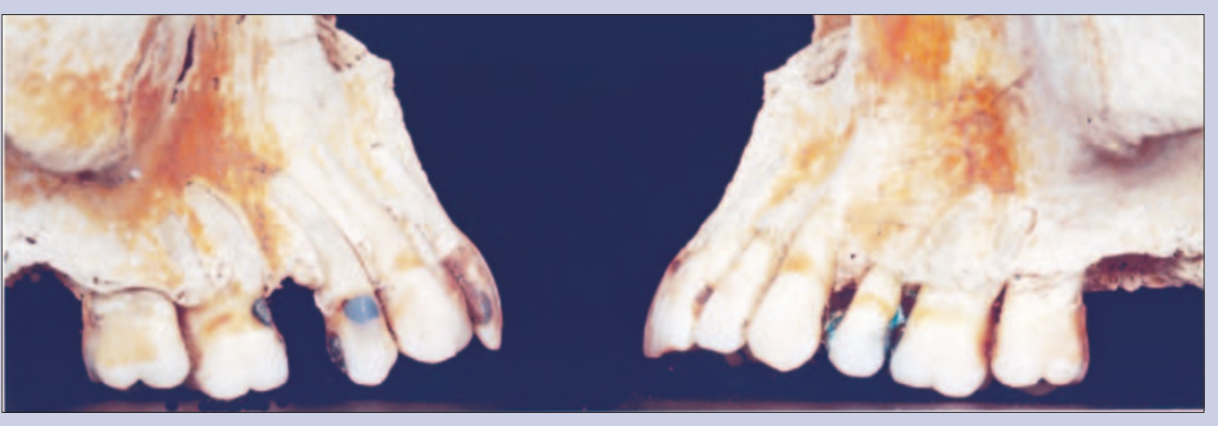
teeth to be present except for the absence of both upper third molar teeth, the upper left first premolar tooth and the upper right second premolar tooth. As regards the absent upper third molar teeth, these have either been lost shortly before death, or post mortem. On the left hand side the space for the first premolar has closed whereas on the right hand side the space for the second premolar tooth has been retained.

The deceased had undergone a number of dental restorations including amalgam fillings to the upper left second premolar, upper left first molar, upper left second molar, upper right first premolar, upper right first molar and upper right second molar. Tooth coloured composite restorations are apparent in the upper left lateral incisor and central incisor, the upper right lateral incisor and central incisor.

All teeth present appear to have extrinsic staining and there is evidence of horizontal bone loss around all of the maxillary teeth, indicating that the deceased was likely to have suffered with chronic periodontal disease and associated gingival recession.

Abrasion features/cavities are apparent at the enamel-dentine junction particularly affecting the upper left canine, premolar and molar teeth. This is likely to be the result of tooth brushing over many years and the wear pattern is likely to be the result of a right handed individual. OPG radiographs demonstrate there is no evidence of any root canal fillings and confirm a picture of horizontal bone loss and no obvious signs of periapical pathology.

Anyone with information pertaining to the inquiry should contact Ric Parsons, HM Coroners Officer, on 01803655255 (Fax 01803655 267)
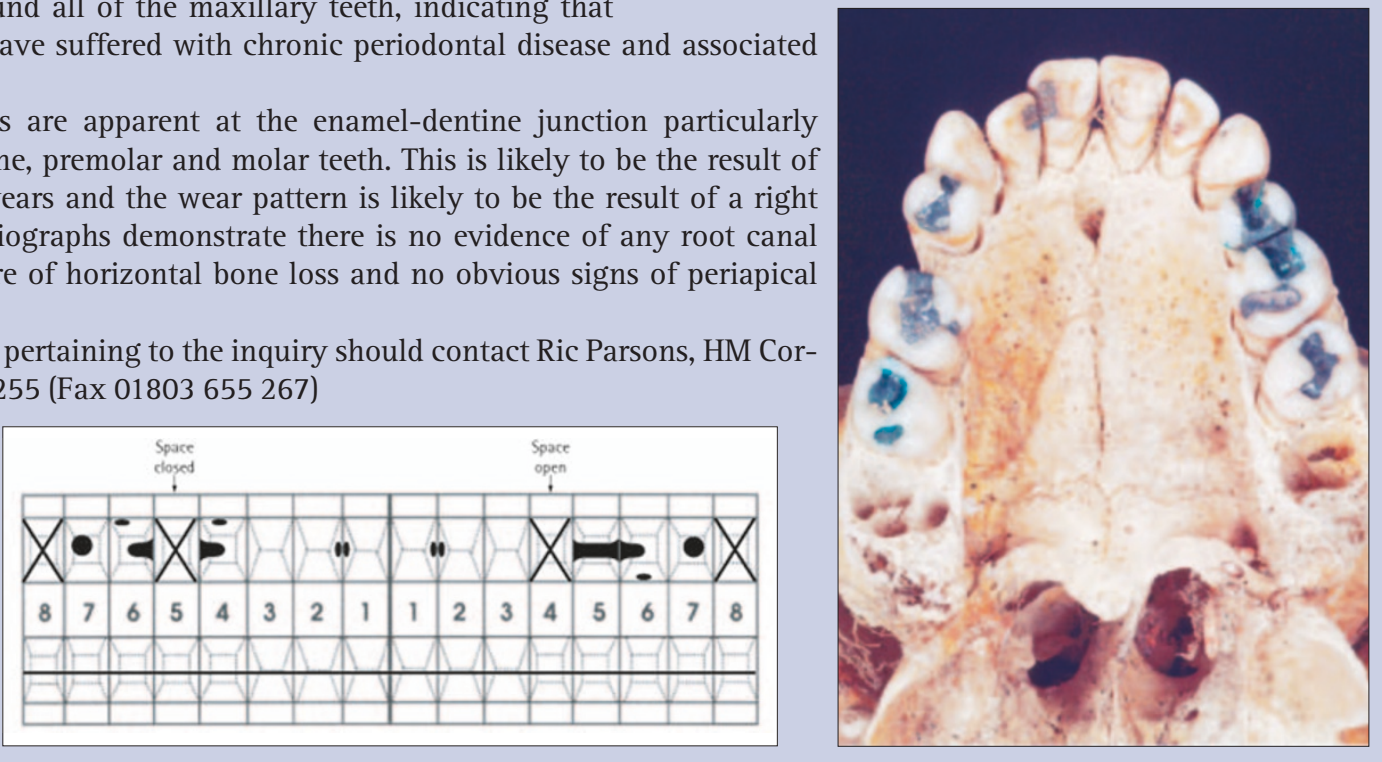

\section{Disability, drugs and dental management}

The British Society of Gerodontology in collaboration with the All Wales Special Interest Group held its Spring Scientific Meeting last month with the theme 'Disability, Drugs and Dental Management in the management of patients with stroke and Parkinson's Dis-

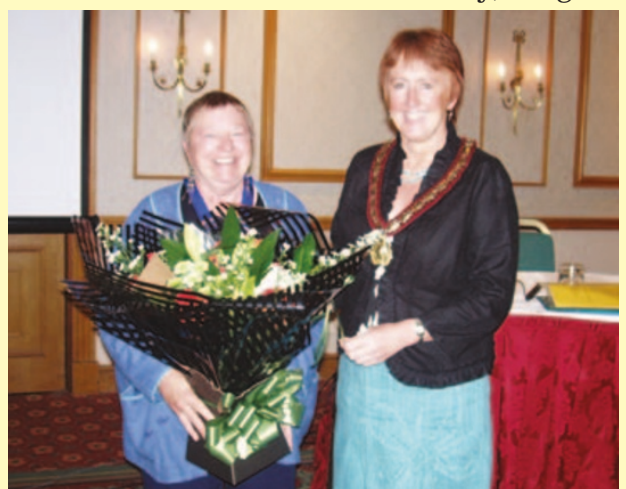
ease'. It was based on recommendations in the National Service Framework for Older People launched by the Welsh Assembly Government in March. Speakers included Helen Howson, Head of Chronic and Community Health Policy, Dr Gladys Tinker OBE, Dr Dwarak Sastry OBE, Professor Mike Lewis, Dr David Davis and Dr Pauline Watt-Smith.

The meeting was chaired by Janet Griffiths, Honorary President of the British Society of Gerodontology. Janet is an Associate Specialist in the University Dental Hospital; she is pictured presenting a bouquet to Sue Greening, Honorary President of the British Dental Association who was invited as a guest to the meeting. Sue Greening is also employed in Wales as a Senior Community Dentist in Gwent and is a graduate of Cardiff University School of Dentistry

Janet Griffiths (left) Sue Greening (right) 


\section{Periodontal bacteria linked to heart disease}

August

International Expodental: a presentation of the Italian Dental Industry

Venue: British Dental Association, Lecture Theatre, 64 Wimpole Street, London W1G $8 Y S$

Date: 31 August 2006, 5.00-7.30 pm

Tel: 02074958191

Email: decastro@italchamind.co.uk

September

Moving to private practice

Venue: The Midland Hotel, Manchester

Date: 8 September 2006

www.bda-events.org

The British Society of Paediatric Dentistry Annual Scientific Conference

'The Art \& the Science'

Venue: The Hilton, Leeds City

Date: 12-15 September 2006

www.bspd.co.uk/conf-2006.html

European Society for Oral Laser Applications/ Hellenic Society for Oral Laser Applications 1st Mediterranean Laser Congress

Venue: Hilton Hotel Rhodes Resort, Greece

Date: 21-23 September 2006

Email: esola2006@medacad.org

www.esola.at

FDI Annual World Dental Congress

Venue: Shenzhen, China

Date: 22-25 September 2006

Email: congress@fdiworldental.org

www.fdiworldental.org

The American Dental Association (ADA)

147th ADA Annual Scientific Session and

Marketplace Exhibition

Venue: Mandalay Bay Resort and

Convention Center, Las Vegas

Date: 16-19 October 2006

www.ada.org

October

Preparing for retirement

Venue: Cedar Court Hotel, Harrogate

Date: 6 October 2006

www.bda-events.org

Community Dental Services Group Annual

Presidential and Scientific meeting

Venue: Marriott Forest of Arden Hotel,

Birmingham

Date: 12-13 October 2006

www.bda-events.org
The presence of specific bacteria and combinations of bacteria in periodontal pockets might be an explanation for the relationship between periodontal disease and acute coronary syndrome (ACS), according to a new study published in the Journal of Periodontology. Researchers evaluated 161 subjects diagnosed with ACS and a control group of 161 participants without it. Diagnosis of the ACS group was based on chest pain associated with electrocardiogram changes that were combined with typical patterns of cardiac markers (such as creatine kinase). The control group included people without cardiovascular disease. This included the absence of elevated blood pressure, or the use of statins and beta-blockers.

The amount of oral bacteria was twice as high in the ACS group for the combination of the bacteria streptococci spp, Porphyromonas gingivalis, Tannerella forsythia and Treponema denticola. Specifically, the authors claim that the findings suggest that T. denticola, T. forsythia and streptococci spp are bacteria in a shared infectious etiology for periodontitis and ACS.

"This might be one of several explanations as to why elevated bacteria and the combination of specific pathogens in periodontal pockets can be linked to a history of ACS," said Stefan Renvert, DDS, PhD and Department of Health Sciences, Kristianstad University. "We also found that the amount of periodontal bacteria results in an inflammatory response that elevates the white blood cell counts and high sensitivity C-reactive protein levels, which has also been linked in past studies to heart disease."

It was also found that the extent of alveolar bone loss was significantly greater among subjects with ACS. Seventy-seven percent of the participants in the ACS group and 42 percent in the control group demonstrated evidence of periodontitis. The extent of bone loss was more severe in the ACS group than in the non-ACS group.

Dr Renvert added that another reason people diagnosed with ACS may have higher oral bacteria could be due to their infectious susceptibility and lack of an adequate host inflammatory response, which may induce other systemic vascular effects participating in the onset of ACS.

"Although this study supports past findings, further research is needed to evaluate the effects of reducing specific bacteria such as $T$. forsythia and T. denticola on reducing the risk for ACS," said Kenneth A. Krebs, DMD and American Academy of Periodontology president. "This data highlights the importance of routine periodontal examinations and at-home dental care."

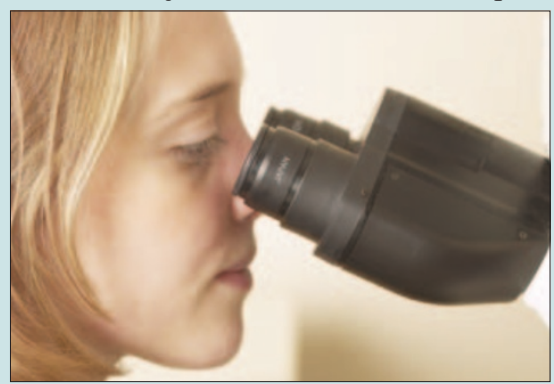

\section{Pharmacology award for Newcastle lecturer}

Dr John G Meechan, Senior Lecturer in Oral and Maxillofacial Surgery at the University of Newcastle-upon-Tyne, has been presented with the 2006 Pharmacology, Therapeutics, and Toxicology Research Award, at the opening ceremonies of the 84th General Session of the International Association for Dental Research (IADR). The award, supported by Wyeth Consumer Healthcare, is one of 15 Distinguished Scientist Awards conferred annually by the IADR

Dr Meechan's research interests have focused on the topic of local anesthesia and pain control in dentistry. His work has been recognised by the British Association of Oral and Maxillofacial Surgeons and the Royal College of Physicians and Surgeons of Glasgow. In addition to and as an expansion of his work on local anesthesia, he has been concentrating his publications in the area of the medically compromised patient. This has led to a series of well-received articles published in the British Dental Journal on the medically compromised patient and the implications for dental care management. The IADR Pharmacology, Therapeutics, and Toxicology Research Award consists of a cash prize and a plaque.

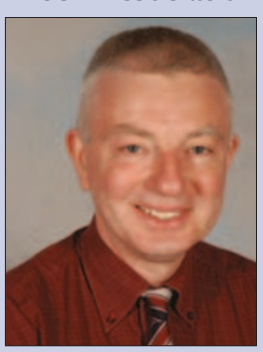




\section{Superbug genome advance}

Superbugs, bacteria resistant to several antibiotics are a major health problem but in the drive to beat the threat they pose, a collaborative team of geneticists have published the genome of the multi-antibiotic-resistant superbug, Clostridium difficile in Nature Genetics (2006 38: 779-786).

The project includes Dr Peter Mullany and Dr Adam Roberts from the UCL Eastman Dental Institute, and scientists from Imperial College London, the London School of Hygiene and Tropical Medicine, University of Nottingham and the Pasteur Institute. Clostridium difficile is the leading cause of hospital-acquired infections in the developed world and is more prevalent and responsible for a greater mortality than MRSA. It is a spore-forming anaerobe, difficult to eradicate and easily spread, thriving when patients are given broad-spectrum antibiotics, and causing a range of diseases from antibiotic-associated diarrhoea to a life-threatening pseudomembranous colitis. It

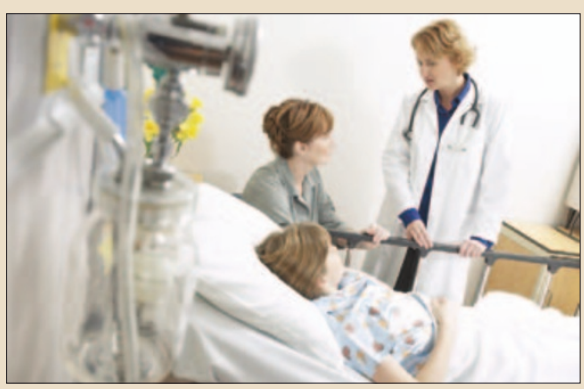

is resistant to several antibiotics and is treatable with only two, metronidazole and vancomycin.

Clostridium difficile is difficult to study in the laboratory and the group's research showed that strains are highly variable in the genes found and that it can readily exchange genes and resistance elements. The team emphasised the need to restrict the use of antibiotics.

\section{Acclaim for a study}

A scientific paper published in the British Orthodontic Society's Journal of Orthodontics was judged by the European Federation of Orthodontics to be the best article published by a member organisation in 2005. The success of the paper is being celebrated by the editor of the journal, Dr Friedy Luther, who submitted it for an award and by the three authors, Drs Maria McNally, David Spary and Peter Rock.

The project arose from an idea by Dr Spary who is Consultant at the Queen's Hospital, Burton on Trent. He had devised an appliance to expand dental arches that was cheaper and easier to fit than commercially produced expansion devices.

Preliminary work for the Prospective Randomised Clinical Trial took place at Birmingham Dental Hospital and the trial was conducted at Queen's Hospital, Burton. It concluded that both expansion devices were equally effective but the custom-made device was cheaper. Laboratory and clinical assessments were made of the two devices according to a study designed by Peter Rock. Maria McNally, a specialist registrar, was named as the project lead and carried out the testing.

The paper "A randomised controlled trials comparing the quadhelix and the expansion arch for the correction of crossbite", has been translated into Spanish and published in the Journal of the Argentinean Orthodontics Society.

Caption: From left to right, David Spary, Maria McNally and Peter Rock

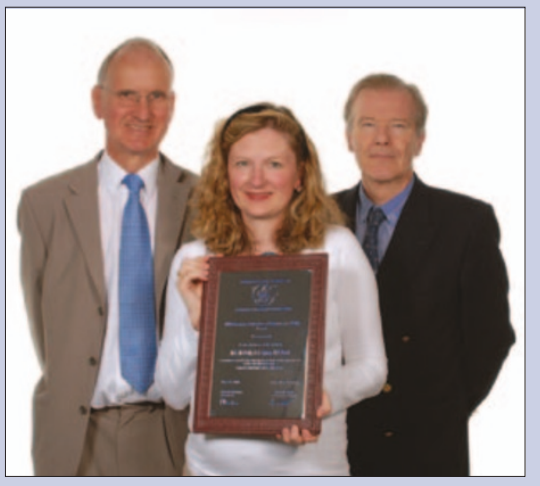

\section{Young scientist wins prize}

A dental student from Kings College Dental Institute, London, has been awarded the IADR David B. Scott Fellowship. This prize is awarded annually by the International

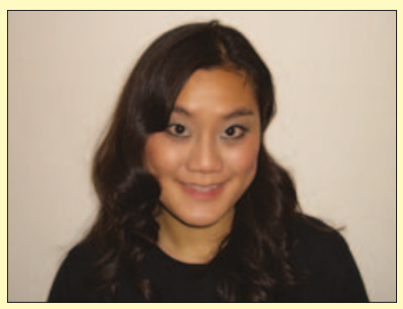
Association of Dental Research to a dental student sponsored by a supervisor. On this occasion, Dr Lucy Di Silvio (Dept. of Biomaterials) presented her student Janet K.C. Kan, to the competition. The prize has allowed them to complete a research project entitled "Tissue engineered bone grafts for mandible augmentation" and participate in the recent IADR 84th General Session in Brisbane, Australia.

\section{Accomplishments recogised at IADR}

The 2006 H. Trendley Dean Memorial Award has been presented to Professor Anthony S. Blinkhorn, of the University of Manchester, UK, during the Opening Ceremonies of the 84th General Session of the International Association for Dental Research (IADR).

Professor Blinkhorn has been the Principal Investigator in many large-scale epidemiological studies, including large dentifrice and water fluoridation studies. The results of these studies have made an important contribution to public health and to the evidence base to support the use of fluoridated toothpaste and water fluoridation in the control of dental caries. Professor Blinkhorn and his team contribute regularly to the Annual Scientific Meetings of the British Society for Dental Research and of IADR, as well as to those of many other international specialist societies. He was the founding president of the IADR's Oral Health Research Group, Chair of the IADR's Behavioral Sciences and Health Services Research Group, and Chair of the Young Investigator Award (2000-2004). Currently, he is General Secretary, Institute of Health Promotion and Education. He is editor of the Health Education Journal, former editor of the International Journal of Health Promotion and Education and a member of the editorial board, British Dental Journal.

In the recent Queen's Birthday Honours List for 2005 in the UK, Professor Blinkhorn was awarded the OBE for his contribution to the promotion of Special Care Dentistry. The H. Trendley Dean Memorial award is presented annually by the IADR and is supported by the Colgate-Palmolive Company and a bequest from the estate of Frank J. McClure in memory of H. Trendley Dean, the 21st President of the IADR and first dental officer of the National Institutes of Health. The award, which consists of a cash prize and a plaque, is conferred for distinguished accomplishments in research and development in the fields of behavioral science, epidemiology, and public health.

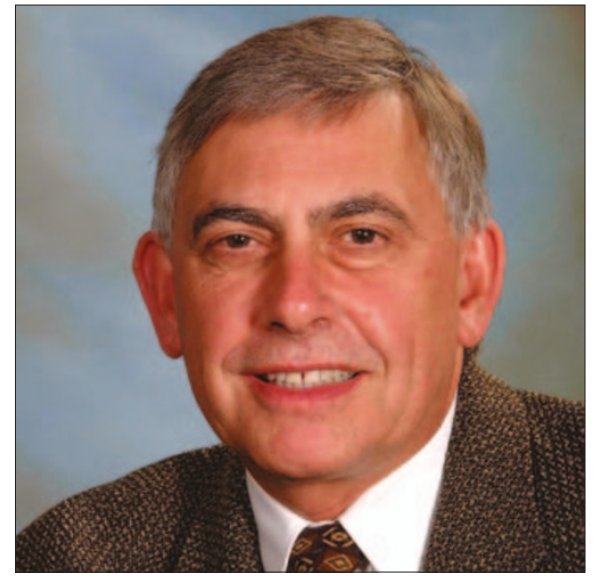

